\title{
It's good to talk: dialogue between strategic environmental assessment and plan-making
}

\begin{abstract}
Literature provides a basis for understanding the relationship between Strategic Environmental Assessment (SEA) and plan-making. This research furthers this by examining dialogue between SEA and plan-making more closely. The research draws on communicative planning, SEA paradigm shifts and theories of power. Four case studies from Scotland and England are analysed via interviews and documentary evidence. It is found that dialogue is constrained by tiered plan-making, pre-existing commitments and political context. Capabilities to enable dialogue can be supported by iteration in SEA and plan-making, and governance structures that bring practitioners together. Contradictions in epistemology are also found to potentially curtail dialogue.
\end{abstract}

\section{Plain Language Summary}

Dialogue between Strategic Environmental Assessment and plan-making are examined through four case studies to consider how dialogue between the two process is constrained or made possible.

\section{Introduction}

The integration of environmental assessment with policy- and decision-making has been identified as an important part of tackling environmental problems since at least the 1980 World Conservation Strategy (International Union for Conservation of Nature and Natural Resources, 1980). Integration of environmental thinking into policy-making was also noted in the World Commission on the Environment and Development report Our Common Future (World Commission on Environment Development, 1987) and Sheate et al. (2003) specifically identified the integration of the environment into strategic decision-making as essential to move towards sustainable development. Moreover, the importance of integrating environmental assessment into policy, plan and programme-making (PPPmaking) and decision-making in order for it to be most successful and more influential has been widely noted (Brown and Therivel, 2000; Kørnøv and Thissen, 2000; Lee and Kirkpatrick, 2000; Nitz and Brown, 2001; Lee, 2006; Fischer, 2007).

Thinking about putting that integration into practice, many have emphasised that Strategic Environmental Assessment (SEA) should be tailored to specific PPP-making and decisionmaking contexts, rather than the converse (Brown and Therivel, 2000; Verheem and Tonk, 
2000; Nitz and Brown, 2001; Sheate et al., 2003; Glasson et al., 2005). However, Lee (2002) noted that a lack of experience conducting SEA at higher tiers of PPP-making has limited opportunities to test the hypothesis that an integrated and tiered assessment system provides significant benefits. This brings us to a situation with support for integration in general but with questions surrounding how SEA should integrate and interact with PPPmaking in practice.

Further questions are raised about the integration of SEA with PPP-making by the shift in the dominant SEA paradigm, potentially changing fundamentally, how SEA interacts with PPP-making. This shift is described as a movement from a rationalist towards a deliberative culture (Lobos and Partidário, 2014). Lobos and Partidário (2014) identified four drivers of change in this SEA paradigm shift - one of which is the potential contribution to collaborative and constructive dialogue. Others have also commented on this evolution, considering or suggesting SEA as knowledge broker and enabling dialogue (Sheate et al. 2003; Sheate and Partidário, 2010), providing critique of options to inform debate (Adelle and Weiland, 2012; Adelle et al., 2012) or contributing to wider deliberative PPP-making processes (IIlsley et al., 2014). Ideas of dialogue and debate also feature in PPP-making literature, for example, Owens and Cowell (2002) noted the potential for dialogue to help plan for sustainable development.

Attention here is of dialogue and communication between the processes of SEA and PPPmaking, typically between professional actors; however, wider debates around public involvement in such dialogue are acknowledged. Dialogue as part of SEA should be situated within broader ideas of collaborative governance (Hajer and Wagenaar, 2003), and specifically for planning, communicative planning, about which Healey $(1998,2006,2012)$ has written extensively. This collaborative and communicative turn contributed to a reorganised governance which emphasised the importance of social dynamic features rather than technical processes, and for planning, raised the focus on how planning was performed, the forming of coalitions, and communication and dialogue (Healey, 2012).

It is with an understanding of this paradigm shift, and a desire to understanding more about how SEA can integrate with and contribute to PPP-making processes that forms the justification and rationale for the focus on enabling or contributing to dialogue in this paper. The research aim of this paper is therefore to examine dialogue between SEA and PPPmaking, and the influential conditions. The paper examines dialogue by considering cases of local and regional plan-making and SEA and Sustainability Appraisal (SA $)^{1}$ in Scotland and England. I first outline key sections of literature to construct the analytical framework.

\footnotetext{
${ }^{1}$ Strategic Environmental Assessment is used as a general term to describe strategic tier environmental assessment as this is the most common term used in literature. However, the term Sustainability Appraisal specifically describes English practice. Further clarification of the Scottish and English terminology is given in the methods section.
} 
Following this, I provide an explanation of the methods used to collect and analyse data. I then present the case study results, followed by discussion with literature, before providing concluding remarks.

\section{Conditions for dialogue}

Literature has been reviewed to identify conditions that can influence the potential for, and dynamics of, SEA PPP-making dialogue. To unpack the conditions for dialogue and think about the dynamics further, discussion first considers literature that outlines the conditions needed for dialogue between SEA and PPP-making. Discussion is then of identified constraints to dialogue, the constellation of actors and positions involved in such dialogue, and the capabilities identified that can foster dialogue. Finally, consideration is of potential contradictions in SEA that may further influence the potential for dialogue.

Sheate and Partidário (2010) identified five practice conditions likely to be required to support SEA in acting as, in their terms, a knowledge broker to support PPP dialogue. These conditions were engaging an appropriate range of stakeholders; having sufficient resources, time and space to enable engagement and knowledge exchange; open and nonjudgemental dialogue; a proponent receptive to external information; and a willingness to use other forms of knowledge (Sheate and Partidário, 2010). Drawing on the work of Fazey et al. (2013) which highlights the importance of context, Saarela et al. (2015) also outlined factors which influence the success of knowledge exchange and knowledge brokerage between SEA and PPP-making. The factors identified were: political context; power relationships, communication and trust between key actors; the level of knowledge of PPPmaking processes by SEA professionals and vice versa; and having sufficient resources (Fazey et al., 2013; Saarela et al., 2015). To understand these conditions and their dynamics, greater attention is needed of how they constrain or enable dialogue.

One of the most fundamental constraints identified when examining the potential for SEA to foster dialogue relates to multiple conditions outlined above, these include the space available for debate, open and non-judgemental dialogue, receptive proponents (Sheate and Partidário, 2010) and communication and trust between key actors (Saarela et al., 2015). Owens and Cowell (2002, p.44) highlighted the difficulty of fostering genuine dialogue within planning, arguing that planning 'affords a somewhat cramped opportunity for dialogue about what constitutes sustainable development'. Allmendinger and Haughton (2012) also argued that there exist clearly defined boundaries and parameters within the planning process that constrain debate. Thinking specifically about the ability of SEA to incorporate strategic thinking and consideration, Bidstrup and Hansen (2014, p.33) echoed the findings of Owens and Cowell (2002), arguing that 'certain institutional contexts simply do not leave room for broad strategic considerations'. Raising the possibility that the space for and openness of debate may be fundamentally constrained.

It is also important to consider the dynamics between actors engaging in dialogue more 
closely to understand conditions related to the range of stakeholders (Saarela et al., 2015; Sheate and Partidário, 2010). Saarela et al. (2015) argued that it is important to understand knowledge exchange not as unidirectional, from SEA to PPP-making, but as reliant on communication between parties that form a constellation of interactions. Kørn $\varnothing \mathrm{V}$ and Thissen (2000) described the network model of decision-making where multi-actor decisions are viewed as negotiations between objectives, problems and solutions. Kickert et al. (1997) also described decision-making as a network, emphasising the importance of the social interactions between actors in the decision-making network. Richardson (2005) argued that multiple values are therefore inevitably part of multi-actor decision-making and as such introduce the need to consider how conflicts are managed and mediated. Understanding dialogue as a constellation of interactions and multidirectional communication between actors therefore emphasises the importance of social and group dynamics.

Moreover, as many descriptions of SEA cite the promotion of sustainable development as part of its rationale (Lee and Walsh, 1992; Glasson et al., 2005; Cashmore et al., 2007; Fischer, 2007), dialogue on politically contentious issues presents SEA with a further complication. However, because any position adopted is unlikely to be universally shared, SEA adopts a position of advocacy (Kørnøv and Thissen, 2000). Owens and Cowell (2002) argued for consideration of the implications of advocacy, particularly if notions of neutrality are held (returned to in greater detail below). Working through this juxtaposition between neutrality and advocacy, Kørnøv and Thissen (2000) described four roles within group decision-making processes. The first two of which, technician and mediator-facilitator, require the adoption of a neutral position, while a policy entrepreneur explicitly supports a decision to further their own objectives and the policy advocate seeks to represent the interests of a particular stakeholder or position (Kørnøv and Thissen, 2000). The role for SEA in dialogue with PPP-making - be that technician, mediator, entrepreneur or advocate therefore, potentially also influences the dynamics of any dialogue.

Potentially providing an overarching influence on dialogue between SEA and PPP-making, power is identified by Saarela et al. (2015) as a further influential condition. Richardson (2005) also argued for the consideration of power to give recognition to the power relations that influence the generation of knowledge, legitimise certain types of knowledge and influence its transmission. Analysing structural power in SEA, Hansen et al. (2013) argued that structuration theory enables and encourages consideration of both constraints and capabilities created by the power dynamics of SEA and PPP-making. Structuration theory places an emphasis on understanding the dualism between structure and agency and on the use of resources to wield power within that context (Giddens, 1984; Hansen et al., 2013). The analysis of Hansen et al. (2013) shifted the focus from SEA report as a moment of information provision to decision makers, onto the moments of communication between SEA and PPP actors, understanding communication as a resource to influence PPP-making with SEA thinking. The emphasise of Hansen et al. (2013) on the importance of interaction and interactivity between actors involved in SEA and PPP-making, and that communication 
can become a resource to exercise power, provides rationale for consideration of both constraints and capabilities to foster dialogue.

Moreover, in thinking about dialogue between SEA and plan-making it is important to briefly consider the potential for dialogue to connect with learning and knowledge exchange (Cowell and Owens, 2006; Jha-Thakur et al., 2009). I argue that the concept of single and double-loop learning, supported by several authors (Jha-Thakur et al., 2009; Adelle and Weiland, 2012), is appropriate to provide insight on SEA and PPP-making dialogue. Singleloop learning is described as adjusting one's actions in response to an observed mismatch between actions and outcomes, while double-loop learning involves more fundamental change to avoid such mismatches in the future (Jha-Thakur et al., 2009). In their analysis of learning and policy assessment, Hertin et al. (2009) also included political use of knowledge - the use of knowledge to support existing political objectives. Saarela et al. (2015) brings these together under instrumental and conceptual success. Instrumental success conceives of direct use of assessment results to either directly change PPPs (single-loop) or to justify PPP positions (political) and conceptual success that results in wider changes in thinking or behaviour (double-loop) (Saarela et al., 2015). Jha-Thakur et al. (2009) noted that the nature of learning can highly differentiated in practice. For example, consultant led SEA can overcome institutional inertia, enabling the introduction of new ideas needed for doubleloop learning, but that this can also lead to problems of organisational memory loss, ultimately hampering the conceptual success of SEA (Jha-Thakur et al., 2009). These understandings of learning raise questions about dialogue between such actors and the conditions needed to achieve learning.

As noted, Sheate and Partidário (2010) identified the need for a willingness to include multiple forms of knowledge as an important condition for successful dialogue. This can be analysed in the light of one of the most influential dynamics of the relationship between SEA and PPP-making; the presence of a technical-rational paradigm connected to the Environmental Impact Assessment roots of SEA (Lobos and Partidário, 2014). The persistence of technical-rational approaches together with calls for SEA to play a role in more deliberative and dialogue oriented PPP-making creates an epistemological contradiction, part of a theory practice divide identified by Lobos and Partidário (2014). Under a technical-rational model, SEA is tasked with providing scientifically rigorous information on likely impacts for use in PPP and decision-making and has been commonly cited as a purpose of various types of assessment (Brown and Therivel, 2000; Cashmore, 2004; Fischer, 2007). Deliberative PPP-making approaches call for SEA to assist in the collection and negotiation of alternative forms of knowledge and perspectives (for example, the views of local communities), going beyond provision of objective information (Illsley et al., 2014). Hertin et al. (2009) noted a reluctance to incorporate knowledge generated by structured qualitative approaches, such as decision trees or impact matrices in policy assessment, and similarly explained this as related to expectations for assessment to utilise precise, neutral and comprehensive information. 
The co-existence of these two views of SEA (both technical-rational and deliberative) and how it can or should contribute to PPP-making creates an epistemological contradiction in the type of knowledge deemed legitimate and valid as part of SEA and PPP-making. The need for a willingness to accept other forms of knowledge identified by Sheate and Partidário (2010) therefore, arguably, requires resolution of this contradiction if dialogue drawing on multiple forms of knowledge is to be possible and feature meaningfully.

Beyond the primacy given to technical scientific information is the assumption that such rigorous information will produce better decisions through a process of rational choice between alternatives (Kørnøv and Thissen, 2000). However, authors from both policy assessment and environmental assessment literature have questioned the technical-rational assumptions behind this, citing a failure to incorporate the complexity of PPP-making and decision-making (Adelle and Weiland, 2012) and the normative basis of such rational assumptions (Weston, 2004). Others have also pointed to similar assumptions of rationality more broadly in planning (Fischer, 2003; Elling, 2009).

Exacerbating inappropriate assumptions of rationality, it has also been argued that following a rational planning or decision-making process does not ensure selection of the outcome that best achieves one's objectives (Verma, 1996; Kørnøv and Thissen, 2000; Cashmore et al., 2008). Leading Kørnøv and Thissen (2000) to distinguish between functional rationality, where rational processes are followed, and substantive rationality, the rational selection of an option to achieve a desired outcome. Creating a further contradiction in the SEA PPPmaking relationship between assumptions of rationality and the complexities of decisionmaking. Indeed, Hertin et al. (2009) explored the question of whether learning from policy assessment by policy makers was possible across what they term the gap between 'rational' conceptualisations of policy assessment and the 'messy reality'. They concluded that for policy assessment this lack of resolution acted as a substantial barrier to learning (Hertin et al., 2009).

Furthermore, it is also argued to be problematic to assume rationality is possible for processes like SEA and PPP-making that are associated with politically contentious and flexible terms like sustainable development and sustainability. Saarela et al. (2015) noted that the political context has a significant influence on dialogue between the two processes. Moreover, Kørnøv and Thissen (2000) argued that a rational conception is only likely to be successful when considerable social consensus exists along with ample knowledge. Lower social consensus, greater conflict of opinion, a lack of knowledge, high uncertainty, multiple objectives with unclear preferences, and the influence of human behaviour, value judgements and specific norms all serve to reduce the appropriateness of a simplistic rational view of decision-making (Verma, 1996; Kørnøv and Thissen, 2000). Hertin et al. (2009) also argued that political use of knowledge in policy assessment demonstrates multiple forms of rationality whereby different political contexts and decision-making contexts influence how science and knowledge are used. 
Through this review of literature, it has been possible to create an analytical framework that emphasises understanding the influential conditions for SEA and PPP-making dialogue. To understand further the dynamics of this dialogue the analytical focus on conditions is organised around three aspects. First, constraints on dialogue are considered, for example, consideration of the space afforded for dialogue, the constellation of stakeholders participating and the position or role for SEA. In addition, as argued by Hansen et al. (2013), ideas of power and structuration theory are included, emphasising the consideration of both constraints and capabilities related to dialogue. The analytical framework therefore moves beyond the confirmation of constraints to analyse capabilities to generate SEA PPPmaking dialogue. Finally, the analytical framework also considers how an SEA paradigm shift and epistemological contradictions may influence dialogue through the creation of contradictions related to knowledge production, rationality and neutrality.

\section{Methods}

This paper is based on data collected from two case studies of SEA in Scotland and two of SA in England. To allow succinct discussion the term 'SEA/SA' is used to refer to practice in Scotland and England, although the original wording has been maintained in quotations. Although SEA and SA are distinct in specific ways, because they both respond to the SEA Directive ${ }^{2}$, they are considered sufficiently similar to enable common discussion with regard to how dialogue features in the relationship with plan-making. Further discussion of the distinction in SEA and SA practice in the Scotland and England can be found in Hayes et al. (2017).

Case studies are able to provide an understanding of complex phenomena and real-world events where a holistic view is sought (Yin, 2009). A case study approach was employed in this research to gain an understanding of the conditions that shape dialogue between SEA/SA and plan-making. Multiple cases were selected to enable examination of variation in practice. It is stressed that multiple cases were not selected to enable universal generalisation, but rather theoretical generalisation whereby conclusions and findings are very much context dependent and theoretical generalisation may be possible based on an understanding of the receiving context (Levi-Faur, 2006).

Four cases were selected, the Black Country Joint Core Strategy, Tunbridge Wells Core Strategy, Falkirk Local Plan and the TAYplan Strategic Development Plan. The cases were selected to provide variation in experience of SEA/SA; in size of team, with some cases working collaboratively and others as single authorities; and the use of consultants and inhouse practice (see Figure 1 and Table 1). Moreover, cases were selected to investigate the conditions for and surrounding dialogue, rather than as exemplars of good dialogue leading to improved outcomes. While some time has passed since the completion of the case

\footnotetext{
2 'SEA Directive' is the term used to refer to Directive 2001/42/EC on the assessment of the effects of certain plans and programmes on the environment.
} 
studies, it is argued that they represent a useful data set given the depth achieved in data collection, and the continued relevance of the case study practice to further our understanding of dialogue between SEA/SA and plan-making.

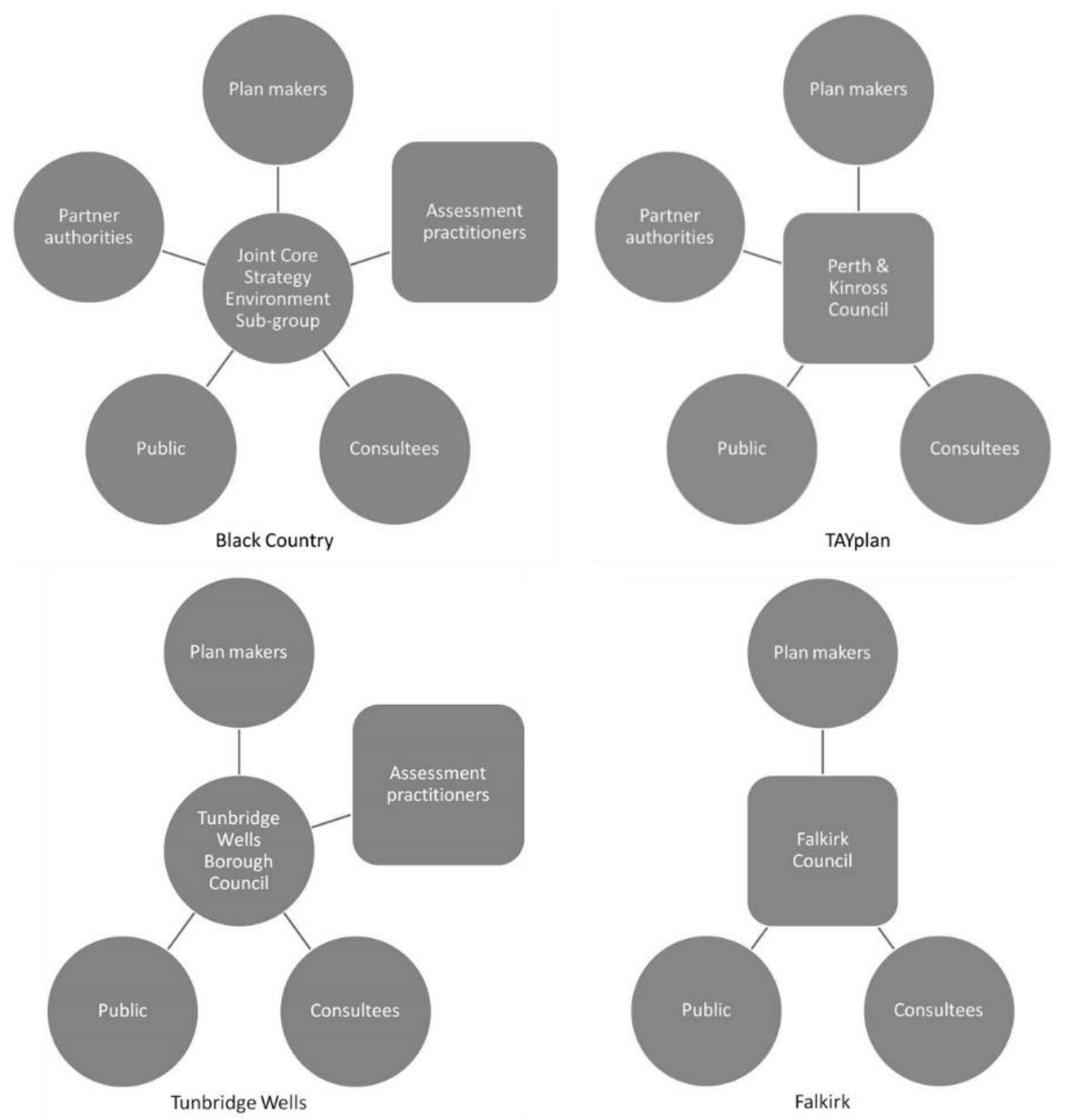

Figure 1: SEA/SA network maps for each case showing the relationship between assessment co-ordinator (centre), assessment practitioners (square), plan makers, consultees and the public. 
Table 1: Case study context information indicating plan scale and where relevant Local Authority partners

Black Country Joint Core Strategy SA

- Sub-regional scale

- Conducted between $2006-2011$

- Assessment done by consultants

- Collaboration of Local Authorities:

- Dudley Metropolitan Borough Council

- Sandwell Metropolitan Borough Council

- Walsall Council

- Wolverhampton City Council

Tunbridge Wells Core Strategy SA

- Local scale

- Conducted between $2005-2010$

- Assessment done by consultants
TAYplan Strategic Development Plan SEA

- Regional scale

- Conducted between 2009 - 2012

- Assessment done in-house

- Collaboration of Local Authorities:

- Dundee City Council

- Angus Council

- Perth and Kinross Council

- Fife Council

- Local scale

- Conducted between $2002-2011$

- Assessment done in-house

Data collection was by qualitative, semi-structured interviews and documentary analysis (see Table 2 for interview numbers). Peräkylä and Ruusuvouri (2011, p.529) described interviews as able to gain access to 'areas of reality which would otherwise remain inaccessible', highlighting the ability of interviews to provide access to individuals' experiences and attitudes. This enables consideration of how individuals involved in SEA/SA and plan-making experienced and understand dialogue between the two processes. The research was subject to ethical review and all participants gave their informed consent. As part of this, reference to each interviewee is by case name and an assigned interviewee number. All interview data was used in analysis; however, quotations are used to illustrate findings and therefore not all interviewees are quoted.

\begin{tabular}{|c|c|c|}
\hline \multicolumn{3}{|c|}{ Table 2: Number of interviews conducted by case study } \\
\hline Case study interviews & $\begin{array}{c}\text { Engaged in SEA/SA or plan- } \\
\text { making }\end{array}$ & $\begin{array}{c}\text { Consultee to SEA/SA or plan- } \\
\text { making }\end{array}$ \\
\hline Black Country Joint Core Strategy SA & 4 & 5 \\
\hline Tunbridge Wells Core Strategy SA & 2 & 2 \\
\hline Falkirk Local Plan SEA & 2 & 2 \\
\hline TAYplan SEA & 3 & 1 \\
\hline
\end{tabular}

Documentary analysis enabled access to the formal records of the cases; however, when engaging in documentary analysis one must ask several important questions about the document's content, purpose, author and context (Robson, 2011). Documents included within the analysis were SEA/SA reports from various stages of the processes, planning documents and associated consultation reports.

The analytical approach adopted in this research builds on the qualitative approach taken to data collection and necessarily responds to the nature of qualitative data available and collected in each case study. The analytical approach taken was thematic coding, involving the coding of data and the grouping of codes into themes based on the analytical framework identified through literature review (Robson, 2011). Describing the benefits of thematic analysis, Braun and Clarke (2006) highlighted its ability to provide a rich and detailed account of data, as well as communicating its complexity. 


\section{Analysing conditions for dialogue - constraints, capabilities and contradictions}

Results are presented based on the analytical framework developed around understanding conditions for dialogue between SEA/SA and plan-making, and specifically considering possible constraints, capabilities and contradictions. The case study data provide insight into how these conditions are manifest, and how they shape and influence SEA/SA plan-making dialogue in practice.

\subsection{Constraints}

The focus here is on analysis of the evidence provided by the case studies for possible constraints to dialogue by drawing on constraints identified in existing literature but also by drawing on the work of Hansen et al. (2013) to connect with structuration theory and ideas of power as analytical tools. It has been possible to confirm many of the conditions identified in literature and evidence has been found to understand how they can act to constraints dialogue. The first relates to practical constraints arising from the tiered nature of PPP-making. The Black Country case specifically acknowledges the 'unusually well-defined framework' inherited from previous stages of planning and the influence that had on the development of options (Black Country, Core Strategy Issues and Options Report, p.15). Two interviewees (Black Country, Interviewees 01 and 02 ) also highlighted this constraint, noting that the Core Strategy had taken many cues from higher tier documents and studies.

It was almost as if a lot of the key issues, especially regarding sustainability, had already been tested at inquiry at the regional level and obviously that had been through SA itself, so a lot of those things just filtered down quite organically or quite naturally, without people necessarily thinking consciously about something else having to be produced. (Black Country, Interviewee 01)

Although it is acknowledged that the higher tier planning documents were subject to their own SEA/SA, this extract nonetheless raises questions about whether there was space for discussion of those 'key issues' and the conclusions made about them at higher tiers. Indeed, another Black Country interviewee also described the relationship between the SEA/SA and plan-making as influenced by pre-existing decisions, constraining SEA/SA to checking and ultimately re-affirming these decisions (Black Country, Interviewee 02).

Influence from higher tiers and other strategies is also noted in the Tunbridge Wells case, but also a more general commitment to 'major long-term commitments and initiatives underpinning the current development plan' (Tunbridge Wells, Scoping Report, p.47) again suggesting limits to the scope of discussion regarding the status quo and pre-existing commitments in the borough.

The Falkirk case also highlighted the need to recognise constraints inherited from higher tiers of planning (Falkirk, Interviewee 10; Falkirk, SEA Post Adoption Statement, p.29, 
para.6.3.1). The principle that higher tiers can introduce constraints is also noted in the TAYplan case (TAYplan, Main Issues Report Environmental Report, p.19) and specifically one interviewee argued that SEA/SA and plan-making must conclude in line with national policy.

So you're limited, you end up just repeating a lot of national policy and... basically saying do you agree with national policy or do you think we should do something else? Which is kind of obvious what the answer is. (TAYplan, Interviewee 17)

Rather than suggest that SEA/SA and plan-making should disregard legitimate higher tiers of decision-making, it is argued that the tiered structure constrains discussion as certain decisions take topics 'off the table'; these can then become, in effect, inscrutable aspects of the plan.

The same principle of topics being outside of discussion, and therefore scrutiny, is also seen to influence how options and alternatives are considered. One Black Country interviewee noted the difficulty of engaging plan makers in discussion of plan options and alternatives; again, they acknowledged various constraints in play.

We [consultants] really tried to push just a few very clear [options], one aspirational option, a less aspirational, or one more economic. But basically they [Black Country authorities] knew what they wanted to do in each of the areas, and that is quite common..., so any other options aren't feasible, because of land ownership, financial constraints and all the rest of it. (Black Country, Interviewee 03)

While the Black Country case demonstrates the constraints introduced by higher tiers and existing commitments, the Tunbridge Wells case arguably provides evidence of the political context influencing what can be discussed or included within SEA/SA and plan-making.

I think they [consultants] did try, to some extent, to bring some new aspects of policy. But unfortunately the things that they wanted to try were not things that were ever going to have any support from [elected] members. (Tunbridge Wells, Interviewee 11)

The need for options to be politically acceptable to the elected members of the council adds further detail to our understanding of constraints. Constraints are not only implications of the tiered structure of PPP-making, but also implications of local politics and the views of the plan proponents or decision makers. This emphasises the importance of a receptive proponent, the political context and structural influences on dialogue, but also the way that multiple constraints can coalesce on one point to constrain the discussion of certain topics or options. 
One Falkirk interviewee succinctly summarised the space for discussion and the constraints upon it, describing the expectation that there would be freedom to propose any alternative within SEA/SA as unrealistic.

I think there is a theoretical idea that you come to a plan with a lot of scope and freedom and it's not like that in practice. And I think the SEA sometimes approaches it that way... as if you've got a completely free rein. (Falkirk, Interviewee 09)

The evidence presented here reminds us that SEA/SA and plan-making processes do not enjoy a blank slate; they occupy a space within a hierarchy, are situated within a political context and must respond to their proponents. It is argued that multiple constraints can be seen to converge on certain aspects of discussion, acting cumulatively to constraint discussion of certain topics or options.

It is also found that limited involvement and communication between SEA/SA practitioners and plan-makers can act to constrain dialogue. One Tunbridge Wells interviewee noted that in the example of the development of their Core Strategy there was limited involvement and engagement in SEA/SA from the wider planning team.

...to be honest, it was only really myself and someone else who were involved with [SA]. I don't think anyone else in the team really had any involvement [with the SA]... we just got a report back from the consultants and then we didn't really change very much to be honest. (Tunbridge Wells, Interviewee 11)

The Tunbridge Wells case highlights how the SEA/SA plan-making relationship can, in practice, be between a very small subset of the wider plan-making team. Far from being automatically or necessarily a comprehensive group, the relationship can become effectively a single relationship. Tunbridge Wells Interviewee 11 specifically highlighted the difficulty of conducting and co-ordinating SEA/SA with consultants with whom you do not have direct personal contact.

Trying to deal with an appraisal process through email, I think, is quite difficult... I think it was, 'we'll write the policies, they'll appraise it and tell us what they think'. (Tunbridge Wells, Interviewee 11)

It should be noted that a further Tunbridge Wells interviewee involved with the production of the SA felt the working relationship between the local authority and consultancy was good (Tunbridge Wells, Interviewee 13). This difference in interpretation may reflect different expectations for the relationship; nevertheless, the Tunbridge Wells case, in comparison to the others, does provide evidence that the relationship between SEA/SA and plan-making is not automatically broadly constituted and very few individuals may be in direct contact. It is argued that this limited relationship between SEA/SA and plan-making, 
based on reviewing reports rather than more substantial personal relationships, constrains potential dialogue between SEA/SA and plan-making - a point discussed further in the following section.

In contrast to the minimal relationship described in the Tunbridge Wells case a relatively straightforward network, evidence from the Black Country case, a more complex multipartner network (see fig 1), highlights the difficulty of developing close working relationships and dialogue between multiple partners.

All the way through it is always pretty difficult to get information... If you are carrying out an SA on behalf of a small district council, for example... a rural one, then it is very easy to find that information because there are probably only two people. In the Black Country obviously, first of all there are four authorities, and secondly, within those authorities there are obviously lots of different people you need to know, so... it was difficult. (Black Country, Interviewee 03)

Working across multiple authorities with different structures and strengths of expertise is argued to complicate the sharing of information and the formation of lines of dialogue.

\subsection{Capabilities}

Further to the above-identified constraints and continuing to draw on structuration theory, attention here is on capabilities and how they can be utilised within the dualism of structure and agency to wield power (Giddens, 1984; Hansen et al., 2013). Analysis of the case studies reveals how certain structural and personal conditions can act as capabilities to foster dialogue between SEA/SA and plan-making. Despite identifying the potential for the SEA/SA plan-making relationship to result in limited dialogue, particularly when focused on asynchronous email communication, this is not found to be inevitable. The structured and asynchronous nature of SEA/SA and plan-making stages has the potential to create space for dialogue through iteration.

In the Black Country case, iteration was highlighted by one interviewee when discussing how the SEA/SA had positively and meaningfully interacted with plan-making (Black Country, Interviewee 02).

To ensure a direct and influential input to the process, the SA team assessed an early version of the Preferred Options document (issued in parts between December 2007 and January 2008) as well as assessing the published Preferred Options Consultation Document (March, 2008). This approach enabled the December 2007 draft Preferred Options document to be amended where appropriate to respond to concerns raised by the SA process, and to reflect areas where the SA process suggested could be further improved in sustainability terms. (Black Country, SA of Preferred Options, p.16) 
The Tunbridge Wells case, despite shortcomings in the depth of the relationship, also highlighted the importance of the various stages as points of access for SEA/SA to have input into plan-making. As with the Black Country case, the process included consideration and preparation of interim versions of reports and plans (Tunbridge Wells, SEA Post Adoption Statement, p.11).

Iteration was also identified in the TAYplan case as enabling SEA/SA to have input into the development and refinement of the plan (TAYplan, Post Adoption Statement, p.6; TAYplan, Interviewee 16).

There has been extensive iteration between the SEA process and the preparation of the Main Issues Report. This has enabled the strength of environmental weighting to be brought through in the content of the Main Issues Report. Discussions have sharpened the text of the Main Issues Report, and have allowed for enhancements to the proposed Vision Framework to be incorporated at an early stage. (TAYplan, Main Issues Report Environmental Report, p .103)

Discussion is described as the means by which SEA/SA influences the plan, this discussion being enabled by iteration. The Falkirk case also described a process of debate entered into after periods of consultation on the plan and SEA/SA that considered comments received and proposed responses and modifications (Falkirk, Post Adoption Statement, p.33, para.7.2.5). The iterative nature of SEA/SA and plan-making is argued to provide moments of interaction that provide space for dialogue and discussion of the findings of SEA/SA and the emerging plan.

Further to the potential for formalised iterative stages to provide space for dialogue, albeit potentially constrained, the Black Country case also provides evidence that structural features can help to overcome constraints introduced by the complex network of partners. One interviewee from the Black Country case highlighted the governance structure as crucial to the management and collaborative working of the partner authorities and the consultants - describing this as something they will take forward in future work (Black Country, Interviewee 02). The governance structure included an environment topic group that acted as the client group commissioning the SEA/SA, as well as a plan steering group that maintained 'a handle' on what was happening with the SEA/SA (Black Country, Interviewee 02). Clearly highlighted as important, the governance structure was described as enabling the multiple authorities to maintain knowledge of the ongoing SEA/SA.

In addition to the potential capabilities provided by structural conditions of practice, iteration and governance structures, it is also found that personal relationships and space for informal interaction in between SEA/SA practitioners and plan makers created productive space for dialogue. Building on the analysis of Hansen et al. (2013) which 
identified the use of communication as a resource, here we see an emphasis on personal communication that is more informal and potentially less constrained by the issues of tiered planning and political context.

I think the whole point of this SA, the way it worked well was that we had to get 20 people together on the steering group and get them thinking about sustainability issues throughout [plan formulation]. I think the end point of an SA isn't the report but it is actually how well you got people thinking about [sustainability issues]. (Black Country, Interviewee 03)

This interviewee saw the value of SEA/SA as related to its ability to foster debate and to get people thinking about sustainability issues in the longer term.

Prominent in the discussion of this relationship was the need for plan makers to be "boughtin' to SEA/SA. One Black Country interviewee emphasised the importance of this.

The crucial thing is 1) they understand the SA process, 2) they realise it is not a burden, and 3) that they find it interesting. (Black Country, Interviewee 03)

This interviewee explained that as consultants they were keen to ensure their visibility to the plan-making team and so insisted on sitting on the steering group in order to ensure 'they [the planning team] wouldn't forget us' (Black Country, Interviewee 03). Interviewees in the TAYplan case also noted the importance of the relationship between those conducting SEA/SA and plan makers. In particular, the TAYplan steering group provided good opportunities for the TAYplan authorities to have input into the SEA/SA (TAYplan, Interviewee 16). In the Falkirk case, a close relationship between the individuals responsible for plan-making and SEA/SA was also considered important and valuable.

I think it is very important [that] the plan maker and the people who are assessing that plan are, if not one and the same person, then [are] working in day-to-day contact. (Falkirk, Interviewee 10)

These extracts highlight the interaction between formal structural components, such as governance structures and steering committees, and informal dialogue. Potentially such structures create spaces within which personal relationships and informal dialogue can occur. It is argued that this combination of structural conditions with informal dialogue, in particular governance structures which link SEA/SA practitioners and plan makers, provide space for personal relationships to develop and offer a means to dialogue which is less constrained by tiered planning and political context.

\subsection{Contradictions}

The analysis here seeks to establish evidence of the existence of contradictions, how they may be affecting the potential for dialogue and their relationship with the identified 
constraints and capabilities. Literature describes the persistence of technical-rational perspectives in SEA/SA as well as noting perspectives that aim to incorporate dialogue into plan-making and SEA/SA. This raises the question of a possible epistemological contradiction where different ideas about knowledge production, legitimate knowledge, rationality and neutrality, are present in the same relationship; complicating how SEA/SA relates to planmaking.

Evidence from three of the cases (Black Country, Falkirk and TAYplan) noted distance as a fundamental part of the SEA/SA plan-making relationship. Specifically distance was sought between those producing the plan and those assessing it, therefore potentially affecting the dialogue possible or encouraged between SEA/SA and plan-making.

One Black Country interviewee explained that as consultants, they felt they had been commissioned to provide distance between SEA/SA and plan-making (Black Country, Interviewee 03). Even in the Falkirk and TAYplan cases that used in-house assessment teams, we also see attempts to maintain distance. One Falkirk interviewee explained that while they made an early decision to conduct the assessment in-house, the team deliberately included one member who was not involved in the writing of plan policies to bring independence (Falkirk, Interviewee 09). With regard to the TAYplan case, Interviewee 16 explained that the Strategic Development Planning Authority decided to employ an additional person specifically for the purpose of SEA/SA.

...that person wasn't... involved in writing the policies of the document, so [they were not] too close, too precious about the policy document. [Their] role was to go in and assess it critically or otherwise. (TAYplan, Interviewee 16)

Distance specifically formed part of the justification for the creation of this position, with the notion that distance can provide independence and a critical perspective.

It is argued that the recognition of the importance and value of close working, together with a desire to maintain and build distance into working practices is evidence of the possible contradiction in epistemology. One possible interpretation of the presentation of SEA/SA as independent from plan-making is argued to be a desire to position SEA/SA as objective or neutral process, and feeds into persistent assumptions that assessment results can be used rationally in plan-making rather being part of dialogue and a deliberatively process. It is not argued that this contradiction is so fundamental as to derail the potential for dialogue indeed evidence presented here shows that various capabilities are present which demonstrably enable dialogue between SEA/SA and plan-making. However, it is argued that this complicates the relationship in a manner distinct from identified constraints because it requires the relationship to value and incorporate opposing ways of working and hints at a more fundamental contradiction in how we understand the SEA/SA plan-making 
relationship. Clearly, further evidence and analysis is required to understand fully this contradiction.

\section{Discussion}

This research has enabled close consideration of the way in which SEA/SA relates to planmaking, specifically considering this relationship in the context of a communicative turn in planning and dialogue as part of plan- and decision-making. In such a context, as Healey (2012, p.338) emphasised, understanding the 'microdynamics of social interaction' which come together in plan-making to set agendas, influence opinion and create knowledge becomes crucial. This research has connected this discussion together with similar discussions going on in SEA/SA literature and with empirical evidence drawn from case studies of SEA/SA in plan-making. Bringing such literatures together places an emphasis on understanding social interaction as part of the SEA/SA plan-making relationship and the dynamics of this relationship with regard to enabling dialogue. The analytical framework sought to interrogate the conditions SEA/SA and plan-making provide for dialogue, and specifically the constraints, capabilities and contradictions present.

In investigating constraints, evidence is presented which confirms much of our existing understanding. We see evidence of the constrained space available for dialogue as identified by Owens and Cowell (2002), Allmendinger and Haughton (2012) and Bidstrup and Hansen (2014). Evidence is also presented that open and non-judgemental dialogue and receptive proponents (Sheate and Partidário, 2010) cannot be assumed. Moreover, mechanisms by which these constraints are produced and enacted are also identified. Tiered PPP-making, pre-existing and long-term commitments are found to come together to act with political forces to effectively take certain topics or options 'off the table'. Providing evidence that two-way dialogue and SEA/SA acting as an advocate for positions or options is not always possible. While it is not argued that tiering, pre-existing commitments and the political context are inherently problematic, it is argued that the lack of dialogue on certain options or topics created by such constraints reduces the opportunity for double-loop learning and conceptual success - ultimately reducing the contribution dialogue might make to future PPPs (Jha-Thakur et al., 2009; Saarela et al., 2015).

Further compounding the difficulty of achieving open dialogue between SEA/SA and planmaking appear to be practical difficulties of asynchronous and geographically separate working, often with communication via email and across a dispersed group. However, such procedural constraints bring our discussion to notions of power and capabilities, and aspects of practice identified as important for enabling dialogue between SEA/SA and PPP-making (Hansen et al., 2013; Richardson, 2005; Saarela et al., 2015). The evidence and analysis presented here builds on the analysis of power in SEA/SA by Hansen et al. (2013) which utilised structuration theory, drawing out the importance of both structure and agency to understand power. Evidence from the case studies confirms the understanding of communication as a resource to wield power put forward by Hansen et al. (2013) as we see 
SEA/SA practitioners identifying moments of discussion and dialogue as a means by which they were able to influence plan-making.

Evidence presented here shows the dualism between structure and agency where the two interact in the expression of power (Hansen et al., 2013; Sewell, 1992), but we also see the duality of structure whereby structure is not simply a constraining force, but can also support the use of resources to wield power (Sewell, 1992). It is argued that the iterative nature of SEA/SA and plan-making provides a structure that creates spaces and moments for dialogue. Moreover, it is found that governance structures can ensure contact and a place at the table for SEA/SA practitioners, furthering opportunities and space for SEA/SA to contribute to dialogue. When on views these structural elements together with agency, one can understand communication as a resource wielded by SEA/SA practitioners as agency that is supported by an iterative structure that creates spaces for dialogue. This needs to be considered in conjunction with the above discussion of constraints to dialogue which form further components of structure. This perspective, it is argued, brings an understanding of the complexity of SEA/SA plan-making dialogue, and how structure and agency interact, i.e. how constraints and capabilities interrelate, and that structure should not be considered only as a constraining force.

Recognition of the role played by iteration in support of dialogue is particularly relevant for future SEA/SA practice in England as debate over the practice of plan-making and SEA/SA takes place. A report published by the Local Plan Expert Group (2016) presents the findings of a review process that sought to consider how plan-making could be made more efficient. Recommendations on SEA/SA related to streamlining of SEA and that guidance be revised to remove advice which describes SA as an iterative process, to recast $S A$ as more simply explaining how the plan represents sustainable development (Local Plans Expert Group, 2016, p.51). It is argued here that evidence presented highlights the need to consider the impact changing the iterative nature of SEA/SA might have on the effectiveness of assessment and whether closely bounded assessments allow space for dialogue on sustainable development.

Such changes to the nature and practice of SEA/SA go to the root of what we expect these processes or tools to do as part of plan-making and bring us to a fundamental contradiction. The communicative turn presents a problem for a technical and expert process like SEA/SA, one which has not gone unnoticed, as evidenced by discussions of rationality and changes in SEA paradigm (Fischer, 2003; Kørnøv and Thissen, 2000; Lobos and Partidário, 2014; Weston, 2004). However, as noted, this creates an epistemological contradiction whereby persistent ideas of positivism and rationality conflict with post-positivist and deliberative ideas about knowledge creation and decision-making. Evidence presented here shows the resonance of this contradiction where SEA/SA are expected to engage closely with planmaking in dialogue to influence decision-making, but also to maintain distance and a position of independence to lend apparent objectivity. It is argued that the rational and 
positivist epistemological roots of SEA/SA are pervasive, adding agreement to the conclusion of Lobos and Partidário (2014) that EIA paradigms dominate SEA. It is argued that this dominance creates an epistemological contradiction that curtails the potential for SEA/SA to enable or engage in dialogue on environmental or sustainability issues in planmaking.

\section{Conclusion}

The literature, case study evidence and discussion presented here have enabled consideration of the SEA/SA and plan-making dialogue. The cases provide further evidence to confirm the conditions identified in previous work as important for dialogue (Saarela et al., 2015; Sheate and Partidário, 2010). Adding to this understanding, it is argued that conditions can be understood as constraints, capabilities and contradictions. The cases provide evidence of the constrained space available for dialogue noted by others (see Allmendinger and Haughton, 2012; Bidstrup and Hansen, 2014; Owens and Cowell, 2002), and reveal some of the mechanisms by which that constraint is enacted, including tiered PPP-making, pre-existing commitments and political acceptability. Capabilities have also been explored, gaining an understanding of how communication can be used as a resource (Hansen et al., 2013), how iterative structures create moments for dialogue and governance structures can give SEA/SA practitioners access to plan makers. The use of structuration theory also helps to conceptualise how these elements piece together to represent the duality of structure, as both constraining and supporting, and the dualism of structure and agency, whereby agency is enacted through communication as a resource, and is both constrained and supported by elements of structure. Finally, the underlying epistemological contradiction noted in literature is found to be potentially visible in practice as notions of close working are found alongside desires for demonstrations of distance and independence. The persistence of this contradiction is argued to curtail the potential for SEA/SA to foster open dialogue within plan-making.

Gaining new understanding of the constraints, capabilities and contradictions in SEA/SA and plan-making dialogue provides a better understanding of the multiple influential conditions. Knowing more about dialogue between SEA/SA and plan-making is crucial when considering how our PPP- and decision-making processes and systems could be improved or changed. As shifts in plan-making approaches (Healey, 2012) and SEA/SA paradigm (Bidstrup and Hansen, 2014) are observed, the design of systems, provision of guidance and practice will be required to change. However, as we see in England, moves to bring greater efficiency to plan-making may affect the ability of SEA/SA to foster dialogue by removing structures that supports dialogue. It is argued that while change is likely inevitable and necessary, decision makers and practitioners in other contexts (both system and international) should be aware of the influential conditions identified, and the various constraints on, and capabilities for, dialogue between SEA/SA and plan-making. Moreover, contradictions in epistemology in SEA/SA and plan-making should also be considered and further research is required to 
understand how these contradictions may affect practice.

\section{References}

ADELLE, C., JORDAN, A. \& TURNPENNY, J. (2012). Proceeding in Parallel or Drifting Apart? A Systematic Review of Policy Appraisal Research and Practices. Environment and Planning C: Government and Policy. 30, 401-415.

ADELLE, C. \& WEILAND, S. (2012). Policy assessment: the state of the art. Impact Assessment and Project Appraisal. 30, 25-33.

ALLMENDINGER, P. \& HAUGHTON, G. (2012). Post-political spatial planning in England: a crisis of consensus? Transactions of the Institute of British Geographers. 37, 89-103.

BIDSTRUP, M. \& HANSEN, A. M. (2014). The paradox of strategic environmental assessment. Environmental Impact Assessment Review. 47, 29-35.

BRAUN, V. \& CLARKE, V. (2006). Using thematic analysis in psychology. Qualitative Research in Psychology. 3, 77-101.

BROWN, A.L. \& THERIVEL, R. (2000). Principles to guide the development of SEA methodology. Impact Assessment and Project Appraisal. 18, 183-189.

CASHMORE, M. (2004). The role of science in environmental impact assessment: process and procedure versus purpose in the development of theory. Environmental Impact Assessment Review. 24, 403-426.

CASHMORE, M., BOND, A. \& COBB, D. (2007). The contribution of environmental assessment to sustainable development: Toward a richer empirical understanding. Environmental Management. 40, 516-530.

CASHMORE, M., BOND, A. \& COBB, D. (2008). The role and functioning of environmental assessment: Theoretical reflections upon an empirical investigation of causation. Journal of Environmental Management. 88, 1233-1248.

COWELL, R. \& OWENS, S. (2006). Governing space: planning reform and the politics of sustainability. Environment and planning C: government and policy. 24, 403-421.

ELLING, B. (2009). Rationality and effectiveness: does EIA/SEA treat them as synonyms? Impact Assessment \& Project Appraisal. 27, 121-131.

FAZEY, I., EVELY, A.C., REED, M.S., STRINGER, L.C., KRUIJSEN, J., WHITE, P.C.L., NEWSHAM, A., JIN, L., CORTAZZI, M., PHILLIPSON, J., BLACKSTOCK, K., ENTWISTLE, N., SHEATE, W., ARMSTRONG, F., BLACKMORE, C., FAZEY, J., INGRAM, J., GREGSON, J.O.N., LOWE, P., MORTON, S. \& TREVITT, C. (2013). Knowledge exchange: a review and research agenda for environmental management. Environmental Conservation. 40, 19-36.

FISCHER, T. (2003). Strategic environmental assessment in post-modern times. Environmental Impact Assessment Review. 23, 155-170.

FISCHER, T. (2007). Theory and Practice of SEA: towards a more systematic approach, London, Earthscan.

GIDDENS, A. (1984). The constitution of society: Outline of the structuration theory, Cambridge, UK, Polity.

GLASSON, J., THERIVEL, R. \& CHADWICK, A. (2005). Introduction to environmental impact assessment, London, Routledge.

HAJER, M. A. \& WAGENAAR, H. (2003). Deliberative Policy Analysis: Understanding Governance in the Network Society, Cambridge, UK, Cambridge University Press. 
HANSEN, A. M., KøRN ØV, L., CASHMORE, M. \& RICHARDSON, T. (2013). The significance of structural power in Strategic Environmental Assessment. Environmental Impact Assessment Review. 39, 37-45.

HAYES, S. J., BARKER, A. \& JONES, C. E. (2017). Re-Examining the Rationale for Strategic Assessment: An Evaluation of Purpose in Two Systems. Journal of Environmental Assessment Policy and Management. 19(4).

HEALEY, P. (1998). Collaborative Planning in a Stakeholder Society. The Town Planning Review. 69, 1-21.

HEALEY, P. (2006). Collaborative planning: shaping places in fragmented societies, Basingstoke, UK, Palgrave Macmillan.

HEALEY, P. (2012). Communicative Planning: Practices, Concepts, and Rhetorics. In: SANYAL, B., VALE, L.J. \& ROSAN, C.D. (eds.) Planning ideas that matter: livability, territoriality, governance, and reflective practice. Cambridge, Mass., MIT Press.

HERTIN, J., TURNPENNY, J., JORDAN, A., NILSSON, M., RUSSEL, D. \& NYKVIST, B. (2009). Rationalising the Policy Mess? Ex Ante Policy Assessment and the Utilisation of Knowledge in the Policy Process. Environment and Planning A. 41, 1185-1200.

ILLSLEY, B., JACKSON, T. \& DEASLEY, N. (2014). Spheres of public conversation: Experiences in strategic environmental assessment. Environmental Impact Assessment Review. 44, 1-10.

INTERNATIONAL UNION FOR CONSERVATION OF NATURE AND NATURAL RESOURCES (1980). World Conservation Strategy: Living Resource Conservation for Sustainable Development. Gland, Switzerland, IUCN UNEP WWF.

JHA-THAKUR, U., GAZZOLA, P., PEEL, D., FISCHER, T. B. \& KIDD, S. (2009). Effectiveness of strategic environmental assessment - the significance of learning. Impact Assessment and Project Appraisal. 27, 133-144.

KICKERT, W.J.M., KLIJN, E.H. \& KOPPENJAN, J.F.M. (1997). Managing complex networks: strategies for the public sector, London, Sage.

$K \varnothing \mathrm{RN} \varnothing \mathrm{V}$, L. \& THISSEN, W. (2000). Rationality in decision- and policy-making: implications for strategic environmental assessment. Impact Assessment and Project Appraisal. $18,191-200$.

LEE, N. (2002). Integrated Approaches to Impact Assessment: Substance or Make-Believe? Environmental Assessment Yearbook. Lincoln/Manchester, Institute of Environmental Management and Assessment/EIA Centre, University of Manchester.

LEE, N. (2006). Bridging the gap between theory and practice in integrated assessment. Environmental Impact Assessment Review. 26, 57-78.

LEE, N. \& KIRKPATRICK, C. (2000). Integrated appraisal, decision making and sustainable development: an overview. In: LEE, N. \& KIRKPATRICK, C. (eds.) Sustainable development and integrated appraisal in a developing world. Cheltenham, Edward Elgar.

LEE, N. \& WALSH, F. (1992). SEA: an overview. Project Appraisal. 7, 126-136.

LEVI-FAUR, D. (2006). A Question of Size? A Heuristics for Stepwise Comparative Research Design. In: RIHOUX, B. \& GRIMM, H. (eds.) Innovative Comparative Methods for Policy Analysis: Beyond the Quantitative-Qualitative Divide. New York, Springer.

LOBOS, V. \& PARTIDÁRIO, M. (2014). Theory versus practice in strategic environmental assessment (SEA). Environmental Impact Assessment Review. 48, 34-46.

LOCAL PLANS EXPERT GROUP (2016). Local Plans: Report to the Communities Secretary and to the Minister of Housing and Planning Local Plans Expert group. 
NITZ, T. \& BROWN, A. (2001). SEA Must Learn How Policy Making Works. Journal of Environmental Assessment Policy \& Management. 3, 329-342.

OWENS, S. \& COWELL, R. (2002). Land and Limits: Interpreting sustainability in the planning process, London, Routledge.

PERÄKYLÄ, A. \& RUUSUVOURI, J. (2011). Analyzing Talk and Text. In: DENZIN, N.K. \& LINCOLN, Y.S. (eds.) The Sage handbook of qualitative research. 4th ed. London, Sage.

RICHARDSON, T. (2005). Environmental assessment and planning theory: four short stories about power, multiple rationality, and ethics. Environmental impact assessment review. 25, 341-365.

ROBSON, C. (2011). Real world research: a resource for users of social research methods in applied settings, Oxford, Wiley-Blackwell.

RUNHAAR, H. \& DRIESSEN, P.P.J. (2007). What makes SEA successful environmental assessment? The role of context in the contribution of SEA to decision-making. Impact Assessment and Project Appraisal. 25, 2-14.

SAARELA, S.R., SÖDERMAN, T. \& LYYTIMÄKI, J. (2015). Knowledge brokerage context factors - What matters in knowledge exchange in impact assessment? Environmental Science \& Policy. 51, 325-337.

SHEATE, W.R., DAGG, S., RICHARDSON, J., ASCHEMANN, R., PALERM, J. \& STEEN, U. (2003). Integrating the environment into strategic decision-making: conceptualizing policy SEA. European Environment. 13, 1-18.

SHEATE, W.R. \& PARTIDÁRIO, M.R. (2010). Strategic approaches and assessment techniques - Potential for knowledge brokerage towards sustainability. Environmental Impact Assessment Review. 30, 278-288.

SEWELL, W. H. (1992). A Theory of Structure: Duality, Agency, and Transformation. American Journal of Sociology. 98, 1-29.

VERHEEM, R. \& TONK, J. (2000). SEA: one concept, multiple forms. Impact Assessment and Project Appraisal. 18, 177-182.

VERMA, N. (1996). Pragmatic Rationality and Planning Theory. Journal of Planning Education and Research. 16, 5-14.

VICENTE, G. \& PARTIDÁRIO, M.R. (2006). SEA-Enhancing communication for better environmental decisions. Environmental Impact Assessment Review. 26, 696-706.

WESTON, J. (2004). EIA in a risk society. Journal of Environmental Planning and Management. 47, 313 - 325.

WILKINS, H. (2003). The need for subjectivity in EIA: discourse as a tool for sustainable development. Environmental Impact Assessment Review. 23, 401-414.

WORLD COMMISSION ON ENVIRONMENT DEVELOPMENT (1987). Our common future, Oxford, Oxford University Press.

YIN, R. (2009). Case Study Research: Design and Methods, London, Sage. 